\title{
Economic Valuation of Recreational and Ecological Resources of Madu Ganga Estuary
}

\author{
Madhubhashini E.T.S. and Warnasuriya T.W.S. \\ Department of Oceanography and Marine Geology, Faculty of Fisheries and Marine Sciences and \\ Technology, University of Ruhuna, Wellamadama, Matara, Sri Lanka \\ *thushanism@gmail.com
}

\begin{abstract}
The Madu Ganga Estuary and mangrove islets are complex coastal habitat ecosystems situated in the Western coast of Galle District in Sri Lanka. The total area of the estuary is 915 ha, of which 770 ha consist of open waters, while islands account for 145 ha. The natural resources in this area are threatened by anthropogenic activities. In a situation where there is no market for such environmental assets, Contingent Valuation Method (CVM) technique can be used to measure the value of environmental services. The objective of this study was estimate economic value of Madu Ganga Estuary and islets.
\end{abstract}

The study was conducted for three months from May to July in 2012 and 450 respondents were surveyed. Among them 15\% were foreigners and 35\% were local tourists. The rest 50\% were the residents in the area who utilised the ecological resources of Madu Ganga Estuary for their livelihoods such as fisheries, cinnamon culture and tourism. Among the visitors 33\% were graduates and $28 \%$ were professional degree holders. The educational attainment of fishers, cinnamon farmers and tourist dependents was comparatively low with $23 \%$ illiterates. The income level of cinnamon farmers was low and 12\% had less than Rs. 4000 per month. The income of fishers and tourist dependents were better with an average of Rs. 8000 per month. Various factors influencing willingness to pay was determined using a linear relationship between the amount of WTP and socio-economic characteristics of the respondents. The household income and gender were the main significant factors that influenced the amount they were willing to pay. The majority of the respondents $(51 \%)$ expressed that conservation of natural resources as the reason for their WTP and 36\% indicated the livelihood support they get from Madu Ganga Estuary area. The acceptable WTP values of cinnamon farmers, fishers, tourist dependents and tourists were Rs.103, Rs.202, Rs.436 and Rs.702 respectively.

Keywords: Contingent valuation method, Willingness to Pay, Gender, Household income 